Volume 9, No.3, May - June 2020

International Journal of Advanced Trends in Computer Science and Engineering

Available Online at http://www.warse.org/IJATCSE/static/pdf/file/ijatcse44932020.pdf

https://doi.org/10.30534/ijatcse/2020/44932020

\title{
Telecontrol of Alternating Current Motor with Star Delta Starter using Computer Network
}

\author{
Heru Supriyono ${ }^{1}$, Ridho Surya Kusuma ${ }^{2}$ \\ ${ }^{1}$ Universitas Muhammadiyah Surakarta, Indonesia, Heru.Supriyono@ums.ac.id \\ ${ }^{2}$ Universitas Muhammadiyah Surakarta, Indonesia, D400150096@ums.ac.id
}

\begin{abstract}
The results of observations in the field indicated that control of AC motor was mainly carried out using manual controllers using a switch. The disadvantage of this manual control is that the operator must walk towards the switch located to turn on or turn off the motor. This publication describes a simple computer-based control for AC motor with star delta starter. The objective of this publication is to turn on and turn off star delta AC motors remotely using telecontrol system. The main controller was developed based on Wemos D1 which will produce a signal to turn on or turn off the motor after receiving commands from the client computer via a wireless local computer network. From the results of the design process, it can be concluded that the computer network based remote control for AC motor with the star delta circuit can be implemented and works well. The experimental results of the connection of the device with a wireless local area network show that the maximum distance between the controller circuit and wifi was 20 meters in the indoor environment and 25 meters in the outdoor environment. The results of the reconnection experiment control circuit after disconnection show the time required for the fastest reconnection was 2.58 seconds while the longest was 8.2 seconds so the average time was 5.49 seconds. When compared with manual control, remote control based on computer networks has a response time 0.13 seconds slower.
\end{abstract}

Key words : Telecontrol, AC motor, induction motor, motor control.

\section{INTRODUCTION}

Motor with alternating current power source or known as AC motor is one type of motor that is very widely used as a source of propulsion in industries such as the steel industry [1] and automotive industry [2]. Most AC motors as an engine in the industry are operated in only two conditions or what is known as on / off control or also sometimes known as start-stop control. The process of turning on and off an AC motor that is most commonly done in the industry is to use a switch device that is connected directly to an AC motor so that the operator or technician must be around the location of the switch (onsite) or must walk towards the switch to turn on and turn off the AC motor.

The development of operational industrial automation technology today refers to the development trend known as the industrial revolution 4.0 which utilizes computer network technology has attracted many researchers for example for optimizing control systems in the industry [3]. Industrial Revolution 4.0 implements a control system based on high-productivity of internet interconnection techniques over ethernet-based networks (with data communication media via unshielded twisted pair (UTP) cables) or wifi [4]. The application of a computer network-based control system allows control process to be done remotely.

The use of internet networks in remote monitoring and control is gaining attention from researchers in various fields for example for monitoring both human health and in industry [5]. In the industrialization of the agricultural sector, computer network-based technology is used to manage data, automate processes, predict situations, and increase many activities, even in real time [6]. The application of the control and monitoring system must also be equipped with a database as a container and information sharing media. Usually the database is managed by a server computer that serves clients or users with a website server interface so they don't overlap [7].

Motor control attracts attention of researchers both onsite control and remote control based on computer networks. In the case of low power motor applications, direct current (DC) motor control over a computer network based on a wireless network using the Zigbee protocol has been reported in [8]. In the case of high power applications synchronous motor control is usually controlled using manual methods [9] or by using Programmable Logic Controller (PLC) [10]. The use of computer networks including the internet of things (IoT) gain broad interest of researchers because IoT facilitates online control and monitoring for example for making smart house [11]. Also, IoT had been proposed for monitoring the condition of AC motors by researchers for example in [12]. The results showed that IoT technology made it possible to continuously monitor motor condition.

The great potential of IoT in the field of AC motor control namely induction motors is also described in the results of the 
study by [13] where researchers used wireless or wifi network for remote control. Research with similar system architecture was also carried out in [14].

Based on the description of the research results above, in this publication, IoT technology was applied to remotely control fort AC motor with star delta starter. The objective of this publication is to turn on and turn off AC motor with star delta starter remotely via a computer network. The benefit of this proposed control system is that it can simplify the motor startup time without having to go to the place where the motor switch is located and press it.

\section{METHOD}

\subsection{Systems Architecture}

The architecture of this computer network based telecontrol system can be seen in the block diagram in Figure 2.

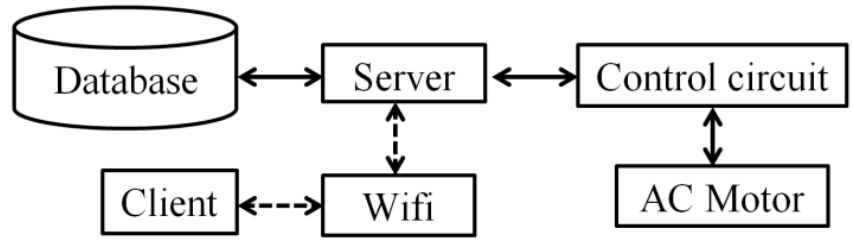

Figure 1: Block Diagram block presenting systems architecture.

The control system has a database created using MySQL which accommodates input conditions, namely logic "1" and logic "0". The control system also has a server that uses a website server interface to connect to the controller circuit. Client is a device, in the developed system is a computer or also a smartphone, which be connected to a server using a wireless local area network using wifi. With this architecture, the client will be able to control the AC motor remotely. The control circuit was built based on microntroller since microcontroller is instrument with small dimension but with high computation ability and have been used in many areas such as detection of gas leakage using wheeled robot[15], portable gas leakage detector[16] and air conditioning control [17]. In this pubication Wemos D1 device, a kind of microcontroller was used as can be seen in Figure 2.

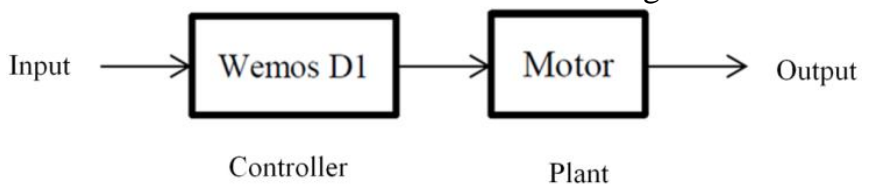

Figure 2: Block diagram showing the arrangement of the controller for AC motor with star delta starter

Wemos D1 will translate the input from the client into a command in the form of electrical signal to turn on or turn off the switches (relays) that ultimately turn on or break the AC motor with a star-delta circuit. The final output of the control system is in the form of motor rotation which is measured in revolution per minute (RPM). What is the actual speed of the
AC motor is not measured continuously because the control system is built using the open loop control system architecture [18].

\subsection{Hardware Design}

The main hardware component in this control is the Wemos D1 and the relay module circuit which will function as a switch to connect and disconnect the electric current from the grid (main power source) to the motor. In the experiment, the control system is equipped with a manual reset to reset the system in case of problems and also a viewer to display the rotating speed of the AC motor. The control device circuit design can be seen in Figure 3 .

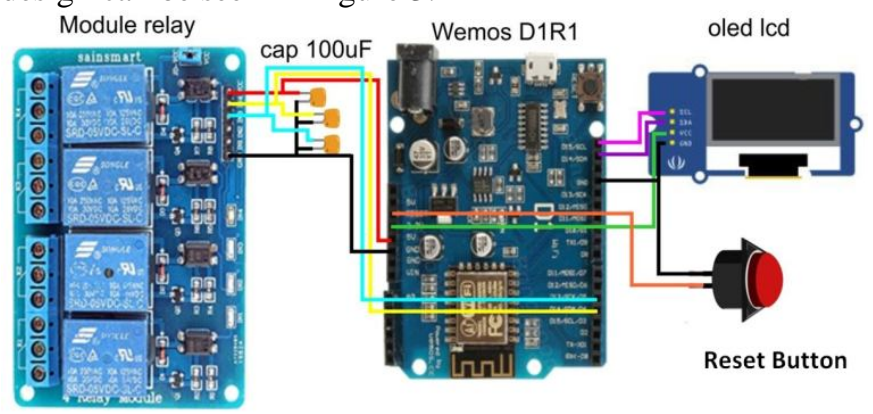

Figure 3: Hardware components and their connections of AC motor control

\subsection{Software Design}

The software on this control system has two parts, i.e. the software created to be run by Wemos D1 and the software on the client (the computer used to control the AC motor). The principle of overall computing stages can be seen in the flowchart diagram depicted in Figure 4.

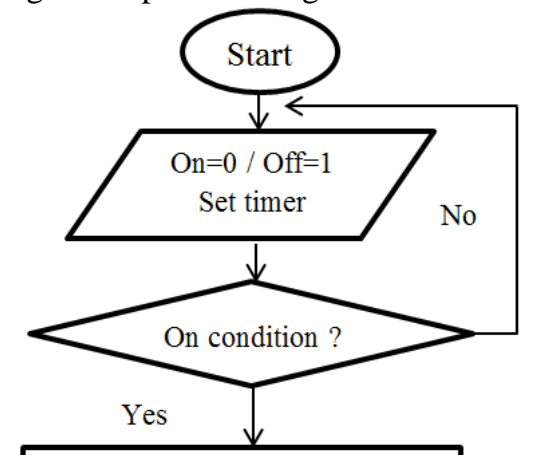

Initially $\mathrm{AC}$ motor start with star as timer goes off then change to

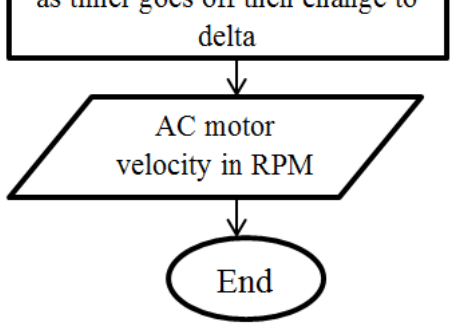

Figure 4: Flowchart presenting general computation steps of control systems 
The Wemos D1 device will always check whether there is a command to start the motor or not. By default, the condition of the motor will be off. If there is a command to start the motor (On condition) then Wemos D1 will generate a command signal to turn on the AC motor with a star starting for some time according to what is written in the program (set timer) then it will turn into a delta starter. The Wemos D1 device then reads the $\mathrm{AC}$ motor rotational speed data generated by sensors on the motor to be displayed on the displaying device. The computational process on the client (computer) and on Wemos D1 can be seen in Figure 5.

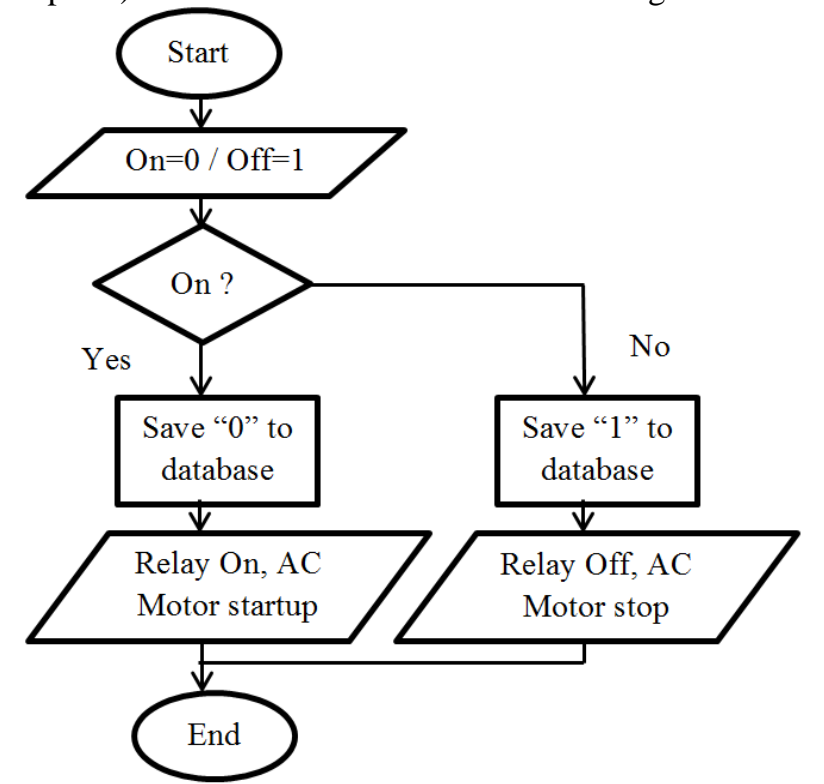

Figure 5: Computation flowchart of computer client and Wemos D1

Figure 8 explains that this software works based on input 1 and 0 , when the condition is " 0 " then the logic is on and if the condition is " 1 " then the logic will be off. The input will be stored in the database, then the controller will execute according to the last input, whether the relay is on or off. Display of the table that are in the database can be seen in Table 1.

Table 1: Data inputed in the database

\begin{tabular}{|c|c|c|}
\hline Id & Data & Description \\
\hline 1 & 1 & $\begin{array}{r}\text { Button one is the button with logic 1 when on } \\
\text { and 0 when off }\end{array}$ \\
\hline 2 & 0 & $\begin{array}{c}\text { Button two is the button with logic 0 when on } \\
\text { and 1 when off }\end{array}$ \\
\hline 3 & 1 & $\begin{array}{c}\text { Button three is the button with logic 1 when } \\
\text { on and 0 when off }\end{array}$ \\
\hline 4 & 0 & $\begin{array}{c}\text { Button four is the button with logic } 0 \text { when } \\
\text { on and 1 when off }\end{array}$ \\
\hline
\end{tabular}

Table 1 is used by the website server to hold data entered by the client (user). The controller checks input data periodically and execute commands. Figure 6 shows the appearance of the web server on the client computer on this control system. Users or operators use client computers that are connected to the LAN network so they can access control from a considerable distance.

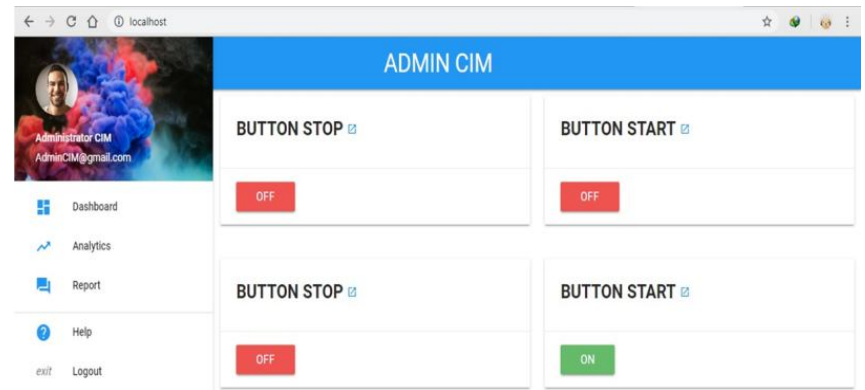

Figure 6: Display of web server of control system

\subsection{Computer Network Configuration}

Based on the system architecture, the implementation of the control systems uses a wireless local area network (WLAN). The controller based on the Wemos D1 device was programmed so that it can be connected to a WLAN based on a WiFi device. Then, the controller will communicate with the router and obtain an IP address to allow the client (user) to access the website server.

\section{RESULTS AND DISCUSSION}

\subsection{Star Delta Circuit of AC Motor Testing}

In the experiments carried out, the first step was setting up of manual AC motor control circuits with star delta starting as shown in Figure 7. Then the circuit was tried to turn on and turn off the AC motor using buttons. Testing was done by using $0.3 \mathrm{KW}$ synchronous $\mathrm{AC}$ motor with star delta starting circuit. Test was carried out repeatedly to ensure that the star delta circuit is working stably.

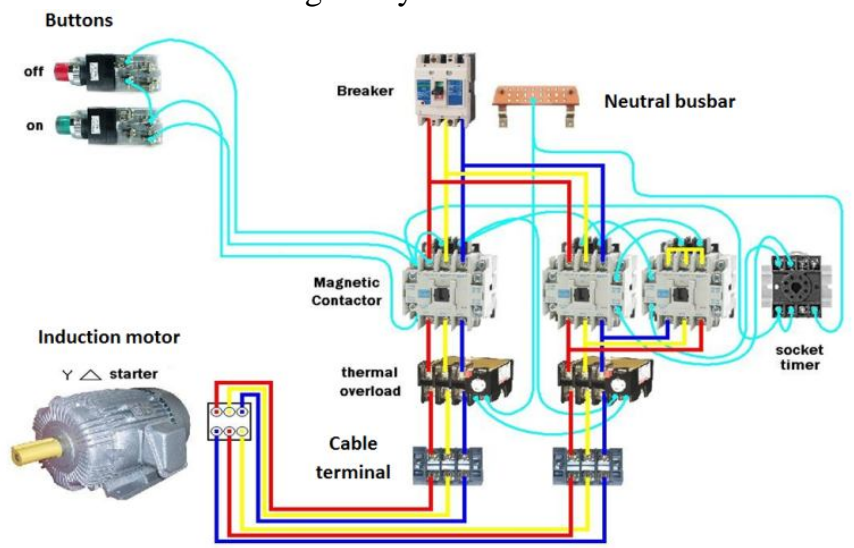

Figure 7: Star delta circuit of AC motor

\subsection{Reconstruction of Whole Systems}

After the manual star delta circuit works properly and was stable, the next step was to replace the manual switch to turn off and turn on the AC motor with the proposed controller circuit that was designed as shown in Figure 8. 


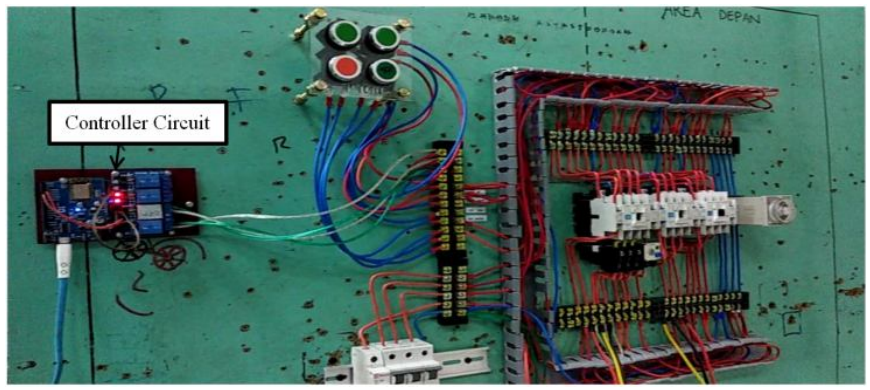

Figure 8: Configuration of a whole systems: the developed controller was connected to star delta circuit of AC motor

Then, a client (computer used by operator) was connected to WLAN via provided wifi or hotspot. Wemos D1 acts as a controller that functions to receive commands from the web server. The command that enters the web server is a command given by the user or operator through the client computer whose appearance can be seen in Figure 9.

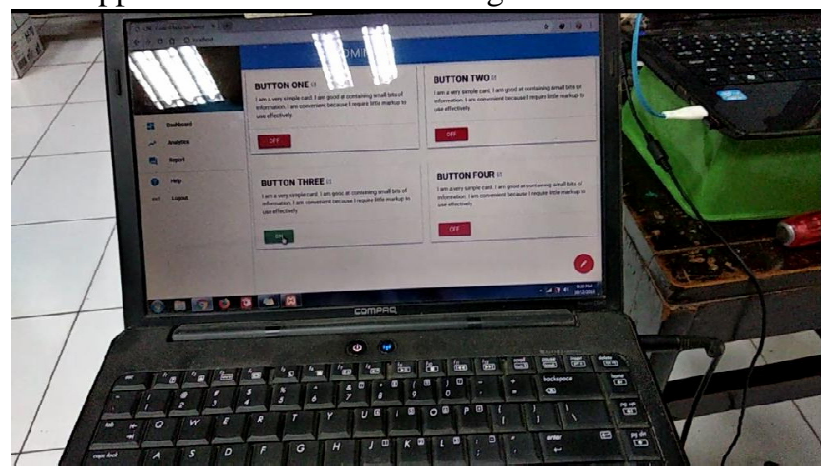

Figure 9: Computer client displaying user interface for controlling $\mathrm{AC}$ motor

\subsection{Telecontrol Testing}

Testing conducted at this stage aims to determine the ability of the developed controller connection with a portable hotspot as a router on a wireless LAN network and understand its connection quality. Testing of controller connections is done based on 3 different conditions namely indoor environment, outdoor environment, and disconnection. Each condition has different kinds and levels of obstacles, namely: (i) indoor environment with walls, doors and furniture barriers, (ii) outdoor environment with weather, trees, and environmental noise barriers, and (iii) disconnection with network termination barriers hotspot for some time. Connection quality conditions were divided into four levels: good, modest (average), bad, and lost. In the experiment, connection quality was said to be good if the time needed for interconnection was between 2-10 seconds, modest (average) if the time needed for interconnection was between 11-20 seconds, bad if the time needed for interconnection was between 21-30 seconds, and lost if the time required for interconnection was greater than 30 seconds.

\section{A. Connection testing in indoor environment}

The results of interconnection testing in the indoor environment can be seen in Table 2 . The experimental results show that the controller could still be connected to a wireless local network at a maximum distance of 20 meters. At this maximum distance, the client computer can still give the command to turn on or turn off but the time required was between 21-30 seconds and the probability of a connection breaking was very large. For more than 20 meters distance the client (computer) was completely unable to give commands to turn on or turn off the AC motor.

Table 2: Connection testing results in indoor environment

\begin{tabular}{|c|c|c|c|}
\hline No. & Distance (meters) & Status & Quality \\
\hline 1. & 2 & Connected & Good \\
\hline 2. & 8 & Connected & Good \\
\hline 3. & 10 & Connected & Good \\
\hline 4. & 16 & Connected & Modest \\
\hline 5. & 20 & Connected & Poor \\
\hline 6. & $>20$ & Connected & Lost \\
\hline
\end{tabular}

\section{B. Connection testing in outdoor environment}

The test results shown in Table 3 show that the designed controller can still be connected to wifi (WLAN) at a maximum distance of 25 meters with poor interconnection quality.

Table 3: Connection testing results in outdoor environment

\begin{tabular}{|c|c|c|c|}
\hline No. & Distance (meters) & Status & Quality \\
\hline 1. & 2 & Connected & Good \\
\hline 2. & 8 & Connected & Good \\
\hline 3. & 10 & Connected & Good \\
\hline 4. & 16 & Connected & Good \\
\hline 5. & 20 & Connected & Modest \\
\hline 6. & 25 & Connected & Poor \\
\hline 7. & 30 & Not Connected & Lost \\
\hline
\end{tabular}

\section{Disconnection testing}

This disconnection test was carried out to determine the time needed to reconnect the remote control device with the wireless local network after it has been disconnected at the specified distance. The test results shown in Table 4 show that in the range of distances with good connections and modest (average) quality from Table 2 and Table 3 the controller took less than 10 seconds to reconnect after being disconnected with the fastest time was 2.58 seconds and the longest time was 8.2 seconds so that the average was 5.49 seconds. The software on Wemos D1 was set to check the connection every one second. 
Heru Supriyono et al., International Journal of Advanced Trends in Computer Science and Engineering, 9(3), May - June 2020, 2769- 2774

Table 4: Time spent for reconnection of controller to wireless LAN

\begin{tabular}{|c|c|c|}
\hline No. & Distance (meters) & Time (second) \\
\hline 1. & 1 & 5.1 \\
\hline 2. & 3 & 8.2 \\
\hline 3. & 9 & 2.58 \\
\hline 4. & 18 & 6.09 \\
\hline & Average & 5.49 \\
\hline
\end{tabular}

\subsection{Comparison Between Manual Control and} Telecontrol

In this test, the time delay difference between control by manual and by using designed telecontrol device was measured. The time delay in this experiment was measured from the moment the switch was pressed until the AC motor starts spinning. The results of the comparison of the average delay between telecontrol and manual control obtained by 5 trials are presented in Table 5.

Table 5: Comparison results of time delay between manual control and telecontrol

\begin{tabular}{|c|c|c|c|}
\hline No. & $\begin{array}{c}\text { Manual Control } \\
\text { (second) }\end{array}$ & $\begin{array}{c}\text { Telecontrol } \\
\text { (second) }\end{array}$ & $\begin{array}{c}\text { Difference } \\
\text { (second) }\end{array}$ \\
\hline 1 & 1.47 & 1.31 & 0.16 \\
\hline 2 & 1.49 & 1.38 & 0.11 \\
\hline 3 & 1.45 & 1.35 & 0.1 \\
\hline 4 & 1.43 & 1.32 & 0.11 \\
\hline 5 & 1.47 & 1.3 & 0.17 \\
\hline \multicolumn{3}{|c|}{ Average } \\
\hline
\end{tabular}

Based on the experimental results in Table 5, it can be seen that the average delay time by using manual control is faster when compared to if it is carried out by controlling using telecontrol with an average delay value difference of 0.13 seconds. However, with the difference in time delay that is not too far away, the designed telecontrol has the opportunity to be used in industrial environment of AC motor control.

\section{CONCLUSION}

From the results of the design, it can be concluded that the computer network based remote control (telecontrol) for AC motor with star delta starter can be implemented and works well. The experimental results of the connection of the device with a wireless local network showed that the maximum distance between the controller circuit with the maximum wifi was 20 meters in the indoor environment and 25 meters in the outdoor environment. The results of the reconnection experiment control circuit after disconnection showed the time required for the fastest reconnection was 2.58 seconds while the slowest was 8.2 seconds so that the average time is 5.49 seconds. When compared with manual control, remote control based on computer networks has a response 0.13 slower. From the results of this experiment, it can be seen that the developed computer-based AC motor telecontrol system has the potential to be implemented in the industrial environment.

\section{REFERENCES}

1. A. K. Paul, I. Banerjee, B. K. Santra, and N. Neogi. Application of AC motors and drives in Steel Industries, in Fifteenth National Power Systems Conference (NPSC), IIT Bombay, December 2008, pp. 159-163.

2. R. G. Shriwastava, M. B. Diagavane, and S. R. Vaishnav, S.R. Literature review of permanent magnet $\mathrm{AC}$ motors drive for automotive application, Buletin Teknik Elektro dan Informatika (Bulletin of Electrical Engineering and Informatics), vol. 1, no. 1, pp. 7-14, 2012. https://doi.org/10.12928/eei.v1i1.220

3. A. Rojko. Industry 4.0 Concept: Background and Overview, International Journal of Interactive Mobile Technologies (iJIM), vol. 11, no. 5, pp. 77-90, 2017. https://doi.org/10.3991/ijim.v11i5.7072

4. M. Hadipour, J. F. Derakhshandeh, M. A. Shiran, and R. Rezaei. Automatic washing system of led street lighting via internet of things, Internet of things, vol. 1, no. $2,74-80.2018$. https://doi.org/10.1016/j.iot.2018.08.006

5. R. R. Adiputra, S. Hadiyoso, and Y. S. Hariyani. Low cost and wearable SpO2 device for health monitoring, IJECE, vol. 8, no. 2, pp. 2088-8708, 2018. https://doi.org/10.11591/ijece.v8i2.pp939-945

6. A. Tzounis, N. Katsoulas, T. Bartzanas, and C. Kittas. Internet of things in agriculture, recent advances and future challenges, Biosystems engineering, vol. 164, pp. 31-48, 2017.

7. C. Kim, H. Kim, J. Lee, and H. Jung. Web server-based distributed machine socialization system, IJECE, vol. 8, no. 2, pp. 2088-8708, 2018. https://doi.org/10.11591/ijece.v8i2.pp631-637

8. M. Reddy, and V. Sawan. Remote monitoring and control system for DC motor using Zigbee protocol, IJAIEM, vol. 3, no. 4, pp. 2319-4847, 2014.

9. Y. Song, and B. Frede. Control of power electronic converters and systems: Single-phase induction motor and AC drives. Aalborg, Denmark: Aalborg University, 2018.

10. A. T. Hammid, Y. K. Hameed, and O. A. Imran. Executing work principle star/delta starter in motor systems using Allen-Bradley PLC, Journal of Engineering and Applied Sciences, vol. 14, no. 6, pp. 1805-1812, 2019. https://doi.org/10.36478/jeasci.2019.1805.1812

11. K. Suresh, P. V. G. D. P. Reddy, and P. Pushkal. Smart Home Services Using Cloud and Internet of Things, International Journal of Advanced Trends in Computer Science and Engineering (IJATCSE), vol. 8, no. 4, pp. 1560-1567, 2019. 
https://doi.org/10.30534/ijatcse/2019/79842019

12. A. Gajbiye, P. Zodpe, Z. Abbas, H. Patanwala, C. Paul, and P. Gadge. IoT based condition monitoring of an induction motor, IOSR Journal of Engineering (IOSRJEN), vol. 2019, pp. 33-40, 2019.

13. Z. Benmabrouk, M. Ben Hamed, and S. Lassaad. Wireless Control for an Induction Motor, International Journal of Electrical and Electronics Engineering, vol. 5, no. 1, 1-5, 2011.

14. V. Seenivasan, K. Ponkumar, R. Venkatraman, J. Jeslindrusilanesamalar. Induction Motor Condition Monitoring and Controlling Based on IoT, International Research Journal of Engineering and Technology (IRJET), vol. 6 no. 3, pp. 7157-7162, 2019.

15. H. Supriyono, and A. N. Hadi. Designing A Wheeled Robot Model For Flammable Gas Leakage Tracking, in Proceedings of The Second International Conference on Informatics and Computing (ICIC), 1-2 November, Aston hotel, Jayapura, Papua (2017), pp. 1-6. https://doi.org/10.1109/IAC.2017.8280657

16. H. Supriyono, E. D. Febriyanto, and K. Harismah. Portable Machine to Machine System for Monitoring Temperature and Flammable Gas of Outdoor Environment, in AIP Conference Proceedings 2114, 040014 (2019), pp. 040014-1 - 040014-8.

17. L. Bulan, R. Liza, L. R. Maderazo, and P. B. Asi. Design and Development of Microcontroller-based Air Conditioning Units Controller as Input to Energy Conservation for University of Batangas, International Journal of Advanced Trends in Computer Science and Engineering (IJATCSE), vol. 8, no. 4, pp. 1020-1025, 2019. https://doi.org/10.30534/ijatcse/2019/06842019

18. K. Ogata. Modern Control Engireening 4th ed. Minnesota, Canada: University of Minnesota, 2002. 